\title{
Delta-9-Tetrahydrocannabinol and Cannabidiol Drug-Drug Interactions
}

\author{
Paul T. Kocis ${ }^{a, b}$ Kent E. Vrana ${ }^{b}$ \\ aDepartment of Pharmacy, Penn State Health, Milton S. Hershey Medical Center, Hershey, PA, USA; \\ ${ }^{b}$ Department of Pharmacology, Penn State College of Medicine, Hershey, PA, USA
}

\section{Keywords}

Tetrahydrocannabinol · Cannabidiol · Drug-drug interactions · Cytochrome P450 - Medical marijuana . Cannabis $\cdot$ Metabolism

\begin{abstract}
Although prescribing information (PI) is often the initial source of information when identifying potential drug-drug interactions, it may only provide a limited number of exemplars or only reference a class of medications without providing any specific medication examples. In the case of medical cannabis and medicinal cannabinoids, this is further complicated by the fact that the increased therapeutic use of marijuana extracts and cannabidiol oil will not have regulatory agency approved PI. The objective of this study was to provide a detailed and comprehensive drug-drug interaction list that is aligned with cannabinoid manufacturer PI. The cannabinoid drug-drug interaction information is listed in this article and online supplementary material as a PRECIPITANT (cannabinoid) medication that either INHIBITS/INDUCES the metabolism or competes for the same SUBSTRATE target (metabolic enzyme) of an OBJECT (OTHER) medication. In addition to a comprehensive list of drug-drug interac-
\end{abstract}

karger@karger.com www.karger.com $/ \mathrm{mca}$ Karger!

\section{(c) 2020 The Author(s)}

Published by S. Karger AG, Basel

This article is licensed under the Creative Commons AttributionNonCommercial-NoDerivatives 4.0 International License (CC BYNC-ND) (http://www.karger.com/Services/OpenAccessLicense). Usage and distribution for commercial purposes as well as any distribution of modified material requires written permission. tions, we also provide a list of 57 prescription medications displaying a narrow therapeutic index that are potentially impacted by concomitant cannabinoid use (whether through prescription use of cannabinoid medications or therapeutic/recreational use of cannabis and its extracts).

(c) 2020 The Author(s)

Published by S. Karger AG, Basel

\section{Introduction}

For decades, there has been scientific interest in the involvement of the endocannabinoid system in the physiological regulation of conditions such as pain, nausea and vomiting, seizures, and multiple sclerosis [1]. The Cannabis sativa plant contains more than 100 phytocannabinoids classified into 11 chemical classes [2-4], of which the psychoactive delta-9-tetrahydrocannabinol $\left(\Delta^{9}\right.$-THC) and the non-intoxicating cannabidiol (CBD) are the compounds most widely studied $[5,6]$. Cannabis sativa still remains illegal at the federal level in the USA; however, as of June 2019, there are 33 States and the District of Columbia that have legalized one or more components of C. sativa [7]. In addition, the 2018 Farm Bill rendered CBD oil (hemp-derived extract) legal as long as its 


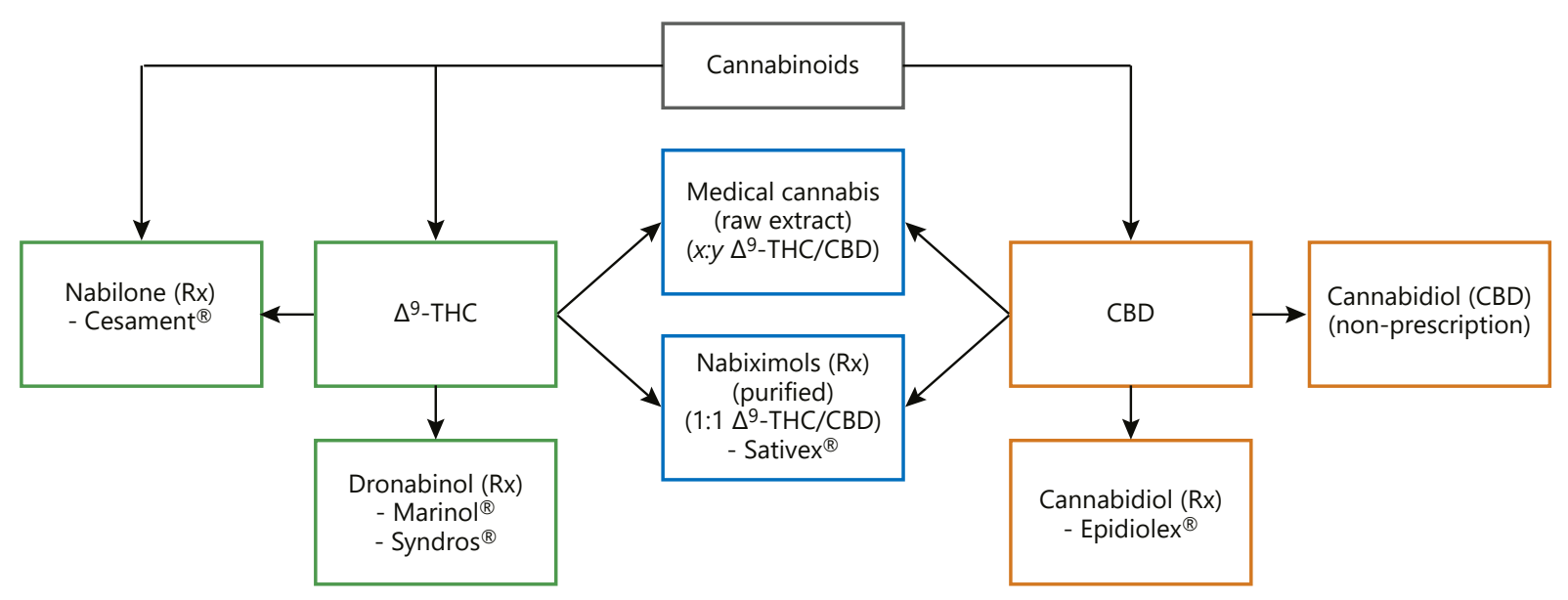

Fig. 1. $\Delta^{9}$-THC and CBD cannabinoid (prescription, OTC, and medical cannabis) formulations.

formulation is derived from hemp from a licensed grower, produced consistently with Federal and State laws, and following specific regulations [8]. Indeed, in November 2019, the U.S. Food and Drug Administration (FDA) sent warning letters to several companies selling CBD-containing products for violating the Federal Food, Drug, and Cosmetic Act regulations concerning false advertising [9].

Cannabinoid-containing products can be inhaled by smoking cigarettes, pipes, water pipes, and emptied cigars and also inhaled (minus the smoke) when vaporized, dabbed, and nebulized. Orally, cannabinoids can be administered by a capsule, oil, solution, or tincture. Additionally, cannabinoids can be mixed in food (i.e., edibles) and eaten as brownies, cookies, and candy or mixed or infused in a drink or brewed into a tea. Cannabinoids can also be administered sublingually and through the oral mucosa route with a lollipop, lozenge, or spray. Topically, cannabinoids can be applied as a gel, cream, ointment, patch, or inserted as a suppository $[10,11]$. Of the 169,036 survey participants in the 2016-2017 "National Survey of Marijuana Use Among U.S. Adults With Medical Conditions," $77.5 \%$ of adult survey participants reported smoking as the primary route of administration [7]. During a 2017-2018 online CBD survey, the most common method of CBD administration was sublingual, followed by vaping, oral ingestion of capsules and liquids, smoking, edibles, and topical administration [4].

From 1995 to 2014, the average percentage composition of $\Delta^{9}$-THC in U.S. Drug Enforcement Agency (DEA) seized recreational marijuana specimens had increased from $\sim 4$ to $\sim 12 \%$ [12]. There are also published reports of adding adulterants, such as tobacco, to cannabis so as to enhance the cannabimimetic effects of $\Delta^{9}$-THC [13]. Reports on CBD manufacturers (that are not being systematically regulated) suggest that labeled CBD formulations frequently do not accurately reflect the stated concentration or actual composition [4]. A report of online retail purchases of CBD suggested that $43 \%$ of products were under-labeled and that $26 \%$ were over-labeled when analyzed for their actual CBD concentration. Indeed, significant amounts of $\Delta^{9}$-THC were detected in $21 \%$ of these CBD oils when it was presumed to have low or undetectable THC levels [14]. In the USA, the concentration of $\Delta^{9}$-THC in hemp-derived CBD cannot exceed $0.3 \%$ [8].

As $\Delta^{9}$-THC and CBD over-the-counter (OTC) products and prescription medications are becoming increasingly available from a pharmacy, dispensary, Internet, local retail store, or by illicit means (Fig. 1), there is an increased likelihood of an unintended drug-druginteraction when coadministered with another herbal, OTC, or prescription medication. It is important to take this into consideration whether the cannabinoid-containing products are used to relieve acute symptoms, in the treatment of a routine medical condition, or during recreational use [15]. The concern for potential drug-drug interactions is of increasing concern and the subject of several recent reviews [16-21].

Although prescribing information (PI) is often the initial source of information, it may only provide a limited number of exemplars or only reference a class of medica-
Kocis/Vrana 
tions without providing any specific medication examples. In the case of medical cannabis and medicinal cannabinoids, this is further complicated by the fact that the increased therapeutic use of marijuana extracts and CBD oil may not have regulatory agency approved PI. In either event, this still prompts the healthcare provider to conduct further research in order to identify potential drugdrug interactions. The objective of this work was to develop a detailed, comprehensive, and updateable drugdrug interaction list that is aligned with the cannabinoid manufacturer PI and further supplemented with the FDA "Drug Development and Drug Interactions: Table of Substrates, Inhibitors and Inducers" online document [22] and the DrugBank database [23].

\section{Prescription $\Delta^{9}$-THC and CBD Cannabinoid Medications}

\section{Dronabinol (Marinol ${ }^{\circledR}$ and Syndros ${ }^{\circledR}$ )}

Dronabinol, a synthetic form of $\Delta^{9}$-THC, is available as either an oral capsule $\left(\right.$ Marinol $\left.^{\circledR}\right)$ or an oral solution $\left(\right.$ Syndros ${ }^{\circledR}$ ). As per the FDA approved manufacturer labeling, both of these dronabinol medications are FDA approved for "the treatment of adults with anorexia associated with weight loss in AIDS and for the treatment of adults with nausea and vomiting associated with cancer chemotherapy who have failed to respond adequately to conventional antiemetic treatments" $[24,25]$.

\section{Nabilone (Cesamet $\left.{ }^{\circledR}\right)$}

Nabilone (Cesamet ${ }^{\circledR}$ ) is a synthetic, but structurally distinct, derivative of $\Delta^{9}$-THC that is available as an oral capsule and has an FDA approved indication for "the treatment of nausea and vomiting associated with cancer chemotherapy in patients who have failed to respond adequately to conventional antiemetic treatments" [26]. It is important to note that the "failed to respond adequately to conventional antiemetic treatments" restriction is required for nabilone, as well as for dronabinol, because of the psychotomimetic reactions not normally observed with other antiemetic agents.

\section{CBD (Epidiolex $\left.{ }^{\circledR}\right)$}

CBD (Epidiolex ${ }^{\circledR}$ ) is a $98 \%$ pure plant-derived oral CBD solution [27], with an FDA approved indication: "For the treatment of seizures associated with LennoxGastaut syndrome or Dravet syndrome in pediatric patients 2 years of age and older" [28].

THC and CBD Drug-Drug Interactions
Nabiximols 1:1 $\Delta^{9}$-THC and CBD (Sativex ${ }^{\circledR}$ )

Sativex ${ }^{\circledR}$, also known by its United States Adopted Name (USAN), nabiximols, is available as a 1:1 $\left(\Delta^{9}\right.$-THC and CBD) plant-derived oral mucosal spray formulation $[29,30]$. Nabiximols is indicated as treatment in more than 25 countries, other than the USA, for "symptom improvement in adult patients with moderate to severe spasticity due to multiple sclerosis who have not responded adequately to other anti-spasticity medication and who demonstrate clinically significant improvement in spasticity-related symptoms during an initial trial of therapy" [29]. In the USA, nabiximols is an investigational drug for polyneuropathy, HIV-associated neuropathy, advanced cancer pain, and palliative care [31].

While the restricted use of prescription cannabinoids presents a potential concern for drug-drug interactions, another major concern arises from the increased use of cannabis and cannabis extracts as therapeutic agents (e.g., medical marijuana and CBD oils). In addition, the increased use of recreational cannabis presents a significant concern for healthcare providers in knowing when to be concerned about unintended drug-drug interactions. These concerns arise because these cannabinoid-containing products can interfere with the metabolism of a large number of other medications, especially those that are required to be maintained in a narrow concentration range in order to obtain clinical benefit without untoward side effects. These medications are said to have a Narrow Therapeutic Index (NTI).

\section{Cannabinoid Metabolism}

Most xenobiotic medications are metabolized by a phase I hepatic cytochrome P450 enzyme (oxidative/ functionalization reaction) and then by a phase II conjugation reaction catalyzed by a hepatic UDP-glucuronosyltransferase (UGT) enzyme $[19,32]$. Combined, these cytochrome P450 and UGT enzymes metabolize more than $90 \%$ of medications that are dependent on hepatic metabolism [32]. The metabolism of the cannabinoids is primarily by the CYP3A4, CYP2C9, and CYP2C19 enzymes and the UGT enzymes, UGT1A9 and UGT2B7 [22, 33].

\section{Cytochrome P450 Enzymes}

Based on the regulatory agency approved PI, CBD, nabiximols, nabilone, and dronabinol are primarily metabolized by 6,6 , 4, and 2 different cytochrome P450 enzymes, respectively. As noted in Table 1, the 3 major 
Table 1. Hepatically expressed cytochrome P450 enzymes

\begin{tabular}{llcccc}
\hline Enzyme & $\begin{array}{l}\text { Hepatic } \\
\text { expression } \\
\text { range, } \\
\text { \% of total }\end{array}$ & Dronabinol & Nabilone & CBD & Nabiximols \\
\hline CYP3A4 & $\mathbf{1 4 . 5 - 3 7 . 0}$ & $\sqrt{ }$ & $\sqrt{ }$ & $\sqrt{ }$ & $\sqrt{ }$ \\
CYP2C8 & $\sim 7.5$ & & $\sqrt{ }$ & $\sqrt{ }$ & $\sqrt{ }$ \\
CYP2E1 & $5.5-16.5$ & & $\sqrt{ }$ & & \\
CYP2C9 & $\mathbf{4 . 5 - 2 9 . 0}$ & $\sqrt{ }$ & $\sqrt{ }$ & $\sqrt{ }$ & $\sqrt{ }$ \\
CYP1A2 & $4.4-16.3$ & & & $\sqrt{ }$ & $\sqrt{ }$ \\
CYP2A6 & $3.5-14.0$ & & & & $\sqrt{ }$ \\
CYP2B6 & $1.7-5.3$ & & & $\sqrt{ }$ & $\sqrt{ }$ \\
CYP2D6 & $1.3-4.3$ & & & $\sqrt{ }$ & $\sqrt{ }$ \\
CYP2C19 & $\mathbf{0 . 9 - 3 . 8}$ & & & & $\sqrt{ }$ \\
CYP2J2 & $<1.0$ & $\sqrt{ }$ & $\sqrt{ }$ & & \\
CYP1A1 & $<1.0$ & & & & \\
CYP1B1 & 0.0 & & & & \\
CYP3A5 & $\sim 1.0$ & & & &
\end{tabular}

The 3 primary cytochrome P450 enzymes (CYP3A4, CYP2C9, and CYP2C19) involved in cannabinoid metabolism are highlighted in bold. CBD, cannabidiol.

cytochrome $\mathrm{P} 450$ enzymes for the cannabinoids are CYP3A4, CYP2C9, and CYP2C19 and account for between 20 and $70 \%$ of the total cytochrome $\mathrm{P} 450$ activity in the liver. Therefore, the ability of the cannabinoids to impact the activity of these enzymes can have dramatic effects on other medications. Note that while other enzymes are capable of metabolizing the compounds (see Table 1), we primarily focus our attention here on these 3 major enzymes (CYP3A4, CYP2C9, and CYP2C19).

\section{UGT Enzymes}

The UGT enzymes serve to catalyze phase II reactions in which the cannabinoids are conjugated to a sugar to render them more readily excreted. There has been little reported on the UGT-dependent conjugation of the cannabinoids with the exception of CBD (Epidiolex ${ }^{\circledR}$ ). In this case, CBD is metabolized by UGT1A9 and UGT2B7 enzymes in the liver and UGT1A7 that is expressed in the gastrointestinal tract [28]. These enzymes comprise only about $13 \%$ of the total UGT activity and so their inhibition or induction may be less impactful globally. There are no references to metabolism by UGT in the other cannabinoid PI; however, it could be assumed that at least nabiximols (Sativex ${ }^{\circledR}$ ) would involve UGT metabolism since it also contains CBD. Moreover, given their shared structures, it is likely that the other cannabinoids are similarly metabolized.

\section{Cytochrome P450 Enzyme INHIBITORS and INDUCERS}

A PRECIPITANT medication can INHIBIT the metabolism of an OBJECT medication by the cytochrome P450 enzyme and/or the UGT enzyme, resulting in an increase $(\uparrow)$ in the OBJECT medication's drug effect and/ or an increase in adverse events. Conversely, the PRECIPITANT medication can INDUCE the metabolism of an OBJECT medication resulting in a decrease $(\downarrow)$ in that medication's effect. In general, this INDUCTION happens when the mRNA for a metabolic enzyme is increased by the PRECIPITATING medication.

\section{Cytochrome P450 Enzyme SUBSTRATES with a NTI}

Cannabinoid-containing products, along with concomitantly prescribed OTC, herbal, or prescription medications, can all compete as the SUBSTRATE for the same metabolic enzyme, thus resulting in an increase in their relative drug concentrations (effectively functioning as INHIBITORS). Although two or more medications may compete as SUBSTRATES for the same enzyme, this may not prove to be clinically significant if there is a wide range of safe therapeutic concentrations and a favorable toxicology profile. Therefore, in order to minimize false alerts and alert fatigue and to provide a manageable and clinically significant list, the SUBSTRATES that have an NTI are emphasized here. Table 2 presents a unified list of NTI medications that will be subject to potential cannabinoid drug-drug interactions of one kind or another. For the most part, they are identified based on CYP2C9, CYP3A4, and CYP2C19. A more complete list of potential drug-drug interactions is provided in the online supplementary material (along with detailed specifics of the enzymes involved). It is also important to note that the cannabinoid (as PRECIPITANT) may affect the metabolism of an OBJECT medication; therefore, Table 2 provides a list of important NTI medications to be closely monitored when coadministered with cannabinoids, either therapeutically or recreationally.

\section{Highly Protein-Bound Medications}

The prescription cannabinoid medications (dronabinol, nabilone, $\mathrm{CBD}$, and nabiximols) are highly protein bound. That is, they are present in the circulation in tight
Kocis/Vrana 
Table 2. List of Narrow Therapeutic Index (NTI) medications to be closely monitored when coadministered with cannabinoids, either therapeutically or recreationally

\begin{tabular}{|c|c|}
\hline Narrow Therapeutic Index (NTI) medication & Enzyme/metabolism \\
\hline acenocoumarol (VKA) & CYP1A2, CYP2C9, CYP2C19, CYP3A4 \\
\hline alfentanil & CYP3A, CYP3A4 \\
\hline aminophylline & CYP1A2, CYP3A4 \\
\hline amiodarone & CYP1A2, CYP2C8, CYP2C19, CYP3A4 \\
\hline amitriptyline & CYP1A2, CYP2B6, CYP2C19, CYP3A4 \\
\hline amphotericin B & Protein binding \\
\hline argatroban & CYP3A4 \\
\hline busulfan & CYP3A4 \\
\hline carbamazepine & CYP1A2, CYP3A4, UGT2B7 \\
\hline clindamycin & CYP3A4 \\
\hline clomipramine & CYP1A2, CYP2B6, CYP2C19, CYP3A4, UGT2B7 \\
\hline clonidine & CYP1A2, CYP3A4 \\
\hline clorindione (VKA) & CYP3A4 \\
\hline cyclobenzaprine & CYP1A2, CYP3A4 \\
\hline cyclosporine & CYP3A4 \\
\hline dabigatran etexilate & UGT1A9, UGT2B7 \\
\hline desipramine & CYP1A2, CYP2B6 \\
\hline dicoumarol (VKA) & CYP2C9 \\
\hline digitoxin & CYP3A4 \\
\hline dihydroergotamine & CYP3A4 \\
\hline diphenadione (VKA) & CYP3A4 \\
\hline dofetilide & CYP3A4 \\
\hline dosulepin & CYP2B6 \\
\hline doxepin & CYP1A2, CYP2C9, CYP2C19, CYP3A4 \\
\hline ergotamine & CYP3A4 \\
\hline esketamine & CYP2B6, CYP3A4 \\
\hline ethinyl estradiol (oral contraceptives) & UGT1A9, UGT2B7 \\
\hline ethosuximide & CYP2E1, CYP3A4 \\
\hline ethyl biscoumacetate (VKA) & CYP3A4 \\
\hline everolimus & CYP3A, CYP3A4 \\
\hline fentanyl & CYP3A4 \\
\hline fluindione (VKA) & CYP2C9, CYP3A4 \\
\hline fosphenytoin & CYP2C8, CYP2C9, CYP2C19, CYP3A4 \\
\hline imipramine & CYP1A2, CYP2B6, CYP2C19, CYP3A4 \\
\hline levothyroxine & CYP3A4 \\
\hline lofepramine & CYP2B6 \\
\hline melitracen & CYP2B6 \\
\hline meperidine & CYP2B6, CYP3A4 \\
\hline mephenytoin & CYP1A2, CYP2C19 \\
\hline mycophenolic acid & UGT1A9, UGT2B7 \\
\hline nortriptyline & CYP1A2, CYP2B6, CYP3A4 \\
\hline paclitaxel & CYP2C8, CYP3A4 \\
\hline phenobarbital & CYP2C19 \\
\hline phenprocoumon (VKA) & CYP2C8, CYP2C9, CYP3A4 \\
\hline phenytoin & CYP2C8, CYP2C9, CYP2C19 \\
\hline pimozide & CYP1A2, CYP3A, CYP3A4 \\
\hline propofol & UGT1A9 \\
\hline quinidine & CYP2C9, CYP2E1, CYP3A4 \\
\hline sirolimus & CYP3A, CYP3A4 \\
\hline tacrolimus & CYP3A, CYP3A4 \\
\hline temsirolimus & CYP3A4 \\
\hline theophylline & CYP1A2, CYP3A4 \\
\hline thiopental & CYP2C19 \\
\hline tianeptine & CYP3A4 \\
\hline trimipramine & CYP2B6 \\
\hline valproic acid & CYP2C9, UGT1A9, UGT2B7 \\
\hline warfarin (VKA) & CYP1A2, CYP2C9, CYP2C19, CYP3A4 \\
\hline
\end{tabular}

VKA, vitamin $\mathrm{K}$ antagonist. 
Table 3. Narrow Therapeutic Index (NTI) and cannabinoid medications with protein binding $\geq 85 \%$

\begin{tabular}{ll}
\hline NTI medications & Protein binding $\geq 85 \%$ \\
\hline amphotericin B $_{\text {cannabidiol }^{\mathrm{a}, \mathrm{b}}}$ & $>90$ \\
cyclosporine $^{\mathrm{a}}$ & $>94$ \\
dronabinol $^{\mathrm{b}}$ & 90 \\
levothyroxine $^{\mathrm{a}}$ & 97 \\
nabilone $^{\mathrm{a}, \mathrm{b}}$ & $>99$ \\
nabiximols $^{\mathrm{a}, \mathrm{b}}$ & $\mathrm{Highly}$ \\
phenytoin $_{\text {c }}$ & $>94$ \\
quinidine & 90 \\
tacrolimus & 88 \\
valproic acid & $>99$ \\
warfarin (VKA) & 85 \\
\hline
\end{tabular}

VKA, vitamin K antagonist; PI, prescribing information. ${ }^{a}$ Not considered an NTI. ${ }^{\mathrm{b}}$ Cannabinoid medication. ${ }^{\mathrm{c}}$ As defined by nabilone $\left(\right.$ Cesamet $^{\circledR}$ ) PI.

Table 4. Smoking INDUCES the metabolism of NTI medications that serve as a CYP1A2 enzyme SUBSTRATE

\author{
acenocoumarol (VKA) \\ aminophylline \\ amiodarone \\ amitriptyline \\ carbamazepine \\ clomipramine \\ clonidine \\ cyclobenzaprine \\ desipramine \\ doxepin \\ imipramine \\ mephenytoin \\ nortriptyline \\ pimozide \\ theophylline \\ warfarin (VKA)
}

VKA, vitamin K antagonist; NTI, Narrow Therapeutic Index.

association with plasma proteins (see Table 3). The percentage used to identify highly protein-bound medications was interpreted from a report by Scheife that states "differences appear to be of slight clinical importance" when protein binding is "less than $80-85 \%$ " [34]. Therefore, when defining highly protein bound in this article, $\geq 85 \%$ protein binding was chosen.

Cannabinoids can displace and hence increase the free fraction of OTHER highly protein-bound medications, especially those that have an NTI and, thus, may require dose adjustments (see Table 3). Conversely, other highly protein-bound medications may have an effect on cannabinoid protein binding and availability. The $\Delta^{9}$-THCderived medication dronabinol (Marinol ${ }^{\circledR}$ and Syn$\operatorname{dros}^{\circledR}$ ) is $97 \%$ protein bound $[24,25]$. The FDA approved PI for the nabilone (Cesamet ${ }^{\circledR}$ ) states "highly bound" but without providing a specific percentage, nor does the DrugBank drug monograph provide a specific percentage of protein binding $[26,30]$. As for CBD (Epidiolex ${ }^{\circledR}$ ), it is $>94 \%$ protein bound as per the FDA PI [28]. The combined 1:1 $\Delta^{9}$-THC and CBD-based medication, nabiximols (Sativex ${ }^{\circledR}$ ), is $>97 \%$ protein bound $\left(\Delta^{9}-\mathrm{THC}\right.$ ) but the Summary of Product Characteristics (SmPC) does not provide a specific percentage of protein binding for the CBD component $[29,30]$.

\section{Tobacco Smoke}

Tobacco smoke contains polycyclic aromatic hydrocarbons that can INDUCE the metabolism of certain medications by the CYP1A1, CYP1A2, and CYP2E1 enzymes [35]. More specifically, smoking produces an inter-individual variability in CYP1A2 activity when metabolizing select medications (e.g., aminophylline, amiodarone, clozapine, and warfarin) [36,37]. Table 4 presents a list of medications where tobacco smoke can INDUCE the metabolism of CYP1A2 SUBSTRATES, with an NTI, that also interact with cannabinoids. In this case, the healthcare provider will want to question the use of tobacco products, as well as reference the cannabinoid drug-drug interaction list (see Table 2).

\section{Source of Drug-Drug Interaction Information}

\section{$P I$}

The U.S. FDA PI information was the initial source of drug-drug interaction information for dronabinol $\left(\right.$ Marinol $^{\circledR}$ and Syndros ${ }^{\circledR}$ ), nabilone $\left(\right.$ Cesamet $\left.^{\circledR}\right)$, and CBD (Epidiolex ${ }^{\circledR}$ ) [24-26]. The SmPC was the initial source of drug-drug interaction information for the combined $\Delta^{9}$-THC and CBD product nabiximols (Sativex $^{\circledR}$ ) [29].

\section{FDA.gov Drug Interaction Table}

Tables within the FDA "Drug Development and Drug Interactions: Table of Substrates, Inhibitors and Inducers" online document [22] were recently revised on December 3rd, 2019. As per the FDA website, these tables
Kocis/Vrana 
provide drug-drug interaction examples and were not intended to be a complete list. See the online supplementary material for a list of FDA defined terms and definitions (e.g., Moderate INHIBITOR and Strong INHIBITOR) that are included in the FDA "Drug Development and Drug Interactions: Table of Substrates, Inhibitors and Inducers" online document [22].

\section{DrugBank.ca Database}

DrugBank (v5.1.4, released on July 2nd, 2019) is a comprehensive drug database sourced from the FDA and Health Canada drug labeling information and from the primary literature of FDA approved, experimental or investigational drugs [23]. The DrugBank database project is supported by the Canadian Institutes of Health Research (CIHR), Alberta Innovates - Health Solutions, and The Metabolomics Innovation Centre (TMIC).

\section{Regulatory Agency Approved PI}

\section{Dronabinol (Marinol ${ }^{\circledR}$ and Syndros ${ }^{\circledR}$ )}

As described in the Marinol ${ }^{\circledR}$ and Syndros ${ }^{\circledR}$ PI, dronabinol is primarily metabolized by the CYP2C 9 and CYP3A4 enzymes (see Table 5) [24, 25]. Other than describing the increased $(\uparrow)$ elimination half-life of pentobarbital by $4 \mathrm{~h}$ for both the Marinol ${ }^{\circledR}$ and Syndros ${ }^{\circledR}$ PI, there are no other medications specifically identified whose metabolism is affected by dronabinol [24, 25]. With the dronabinol PI stating that the enzyme and inhibition potential of dronabinol is not fully understood, it can be assumed that there are potential drug-drug interactions with the CYP2C9 and CYP3A4 SUBSTRATES. In the present context (see Table 2), the CYP2C9 and CYP3A4 SUBSTRATES are limited to those medications that have an NTI and are likely to be affected by $\Delta^{9}$-THC legal or illicit use. A comprehensive list of these drugdrug interactions is provided in the online supplementary material.

\section{Disulfiram-Like Interaction: Dronabinol (Syndros ${ }^{\circledR}$ )}

In addition to the synergistic effect of alcohol (e.g., drowsiness and sedation) with a cannabinoid, the dronabinol (Syndros ${ }^{\circledR}$ ) formulation contains $50 \%$ (w/w) dehydrated alcohol that can precipitate a disulfiram-like reaction (e.g., abdominal cramps, nausea, vomiting, headaches, and flushing) with medications (e.g., disulfiram $\left[\right.$ Antabuse $^{\circledR}$ ] and metronidazole) that inhibit aldehyde dehydrogenase when administered at the same time or within a certain period of time of one another [25].

\section{Nabilone (Cesamet ${ }^{\circledR}$ )}

Nabilone is a synthetic, but structurally distinct derivative of $\Delta^{9}$-THC, and the route and rate of metabolism of its metabolites are similar to those observed with other cannabinoids, including $\Delta^{9}$-THC (dronabinol) [30]. The nabilone PI states that nabilone has a WEAK INHIBITORY effect on CYP2E1 and CYP3A4 and has a MODERATE INHIBITORY effect on CYP2C8 and CYP2C9 [26] (see Table 5). In the "Drug Interaction" section of the nabilone $\left(\right.$ Cesamet $^{\circledR}$ ) PI, there are generalized case reports of central nervous system and cardiovascular adverse events that were only associated with marijuana smoking and not specific to nabilone; therefore, these case reports were not included in this article [26].

\section{CBD (Epidiolex ${ }^{\circledR}$ )}

As described in the CBD (Epidiolex ${ }^{\circledR}$ ) PI, CBD can either INHIBIT or INDUCE the metabolism of OTHER medications serving as a CYP1A2 SUBSTRATE (e.g., theophylline and caffeine) and CYP2B6 SUBSTRATE (e.g., bupropion and efavirenz), resulting in an increase $(\uparrow)$ or decrease $(\downarrow)$ in the OTHER medication's effect (see Table 5). Moreover, CBD can INHIBIT the metabolism of OTHER medications by cytochrome P450 CYP2C8, CYP2C9 (e.g., phenytoin), and CYP2C19 (see Table 5). $\mathrm{CBD}$ can also increase the effect of OTHER medications that are metabolized by CYP2C19 SUBSTRATES (e.g., diazepam). Since this may increase the risk of adverse events, a reduction in dose of the CYP2C19 SUBSTRATE medication should be considered. CBD can also INHIBIT the metabolism of OTHER medications by the UGT1A9 enzyme (e.g., diflunisal, propofol, and fenofibrate) and UGT2B7 enzyme (e.g., gemfibrozil, lamotrigine, morphine, and lorazepam).

Since the coadministration of clobazam with CBD (Epidiolex ${ }^{\circledR}$ ) increases the CBD active metabolite (7-OHCBD) and produces a 3-fold increase in plasma concentrations of N-desmethylclobazam, (the active metabolite of clobazam and a SUBSTRATE of CYP2C19), a reduction in dose of clobazam may need to be considered [28]. When CBD was coadministered with valproate, there was no effect on valproate exposure; however, there is an increased incidence of liver enzyme elevations with a recommendation to discontinue either agent or reduce the dose of either agent [28]. Additionally, the PI states that there is insufficient data to assess the risk of concomitant administration of other hepatotoxic medications and CBD (Epidiolex ${ }^{\circledR}$ ) [28]. 
Nabiximols 1:1 $\Delta^{9}$-THC and CBD (Sativex ${ }^{\circledR}$ )

As described in the SmPC, nabiximols $\left(\right.$ Sativex ${ }^{\circledR}$ ) is a reversible INHIBITOR of CYP3A4, CYP1A2, CYP2B6, CYP2C9, and CYP2C19 at concentrations far in excess of those likely to be achieved clinically [29]. In vitro, nabiximols has potential for time-dependent INHIBITION of CYP3A4 at clinically relevant concentrations. The coadministration of nabiximols with other CYP3A4 SUBSTRATES with an NTI may result in an increase in the effect of the concomitant drug [29]. Nabiximols was also found to INHIBIT UGT1A9 and UGT2B7 at concentrations that could be achieved in clinic. Care should be taken when prescribing nabiximols with concomitant medications solely metabolized by both or either of these UGT enzymes (e.g., propofol and certain antivirals). The $\Delta^{9}$ THC and CBD plasma concentration from clinical doses of nabiximols could be sufficient to INDUCE CYP1A2, CYP2B6, and CYP3A4 at the mRNA level, so a review of the dosing regimen of these medications listed in Table 2 is advised. Additionally, nabiximols can INDUCE the metabolism of hormonal contraceptives.

With nabiximols (Sativex ${ }^{\circledR}$ ) containing approximately $50 \% \mathrm{v} / \mathrm{v}$ of ethanol, each actuation contains up to $0.04 \mathrm{~g}$ of ethanol. The PI states that a small glass of wine (125 $\mathrm{mL}$ ) contains $12 \% \mathrm{v} / \mathrm{v}$ and, thus, contains $12 \mathrm{~g}$ of ethanol [29]. Therefore, most patients taking up to 12 sprays/day would ingest $<0.5 \mathrm{~g}$ of ethanol, and thus, this amount of ethanol is NOT expected to produce a disulfiram-like reaction that is possible with the dronabinol (Syndros ${ }^{\circledR}$ ) alcohol-containing formulation [29].

\section{Cannabinoid Drug-Drug Interactions}

Drug-drug interactions, associated with cannabinoidcontaining products, should not be simply limited to the additional dizziness, confusion, sedation, and somnolence when taken concomitantly with alcohol or other central nervous system-sedating medications (e.g., benzodiazepines, muscle relaxants, barbiturates). Additionally, there can be additive cardiac side effects (e.g., hypotension, hypertension, syncope, and tachycardia) when taken with other medications having similar cardiovascular adverse events.

The cannabinoid frequency of use, route of administration, gastrointestinal absorption, hepatic metabolism, renal excretion, and a patient's genomic profile can all influence the cannabinoid metabolism and influence the extent of a drug-drug interaction and any resulting adverse events. If a potential drug-drug interaction is identi-
Table 5. Cannabinoid medication (as the PRECIPITANT) affecting the metabolic enzyme levels/activity/drug effect of substrate medications (OBJECT) with a Narrow Therapeutic Index (NTI)

\begin{tabular}{|c|c|}
\hline $\begin{array}{l}\text { Cannabinoid } \\
\text { (as PRECIPI- } \\
\text { TANT) }\end{array}$ & $\begin{array}{l}\text { Affects the metabolism of the following } \\
\text { SUBSTRATES with a Narrow Therapeutic } \\
\text { Index (NTI) }\end{array}$ \\
\hline $\begin{array}{l}\text { Dronabinol } \\
\text { Marinol }^{\circledR} \text { and } \\
\left.\text { Syndros }^{\circledR}\right)\end{array}$ & $\begin{array}{l}\text { CYP2C9 SUBSTRATES } \\
\text { CYP3A4 SUBSTRATES }\end{array}$ \\
\hline $\begin{array}{l}\text { Nabilone } \\
\left.\text { (Cesamet }^{\circledR}\right)\end{array}$ & $\begin{array}{l}\text { Nabilone is a (WEAK) INHIBITOR } \\
\text { CYP2E1 SUBSTRATES } \\
\text { CYP3A4 SUBSTRATES } \\
\text { Nabilone is a (MODERATE) INHIBITOR } \\
\text { CYP2C8 SUBSTRATES } \\
\text { CYP2C9 SUBSTRATES }\end{array}$ \\
\hline $\begin{array}{l}\text { CBD } \\
\left(\text { Epidiolex }^{\circledR}\right)\end{array}$ & $\begin{array}{l}\text { CBD INHIBITS and INDUCES } \\
\text { CYP1A2 SUBSTRATES } \\
\text { CYP2B6 SUBSTRATES } \\
\text { CBD INHIBITS } \\
\text { CYP2C8 SUBSTRATES } \\
\text { CYP2C9 SUBSTRATES } \\
\text { CYP2C19 SENSITIVE SUBSTRATES } \\
\text { UGT1A9 SUBSTRATES } \\
\text { UGT2B7 SUBSTRATES }\end{array}$ \\
\hline $\begin{array}{l}\text { Nabiximols } \\
\left(\text { Sativex }^{\circledR}\right)\end{array}$ & $\begin{array}{l}\text { Nabiximols INHIBITS } \\
\text { CYP2C8 SUBSTRATES }^{\text {a }} \\
\text { CYP3A4 SUBSTRATES } \\
\text { UGT1A9 SUBSTRATES } \\
\text { UGT2B7 SUBSTRATES } \\
\text { Nabiximols INDUCES } \\
\text { CYP1A2 SUBSTRATES } \\
\text { CYP2B6 SUBSTRATES } \\
\text { CYP3A4 SUBSTRATES }\end{array}$ \\
\hline
\end{tabular}

CBD, cannabidiol; PI, prescribing information. ${ }^{\text {a }}$ Listed in the CBD (Epidiolex ${ }^{\circledR}$ ) PI.

fied, it does not necessarily translate into a contraindicated combination nor a clinically significant interaction, but an opportunity to evaluate the dose of either the cannabinoid or concomitantly PI.

Clinically relevant drug-drug interactions will generally arise when a cannabinoid INHIBITS, INDUCES, or serves as a competing SUBSTRATE for a metabolic enzyme of an OTC, herbal, or prescription medication. Conversely, metabolism of the cannabinoid-containing medications can be affected by OTHER medications. These drug-drug interactions can be quite complicated when they involve a number of medications, their corresponding metabolizing enzymes, and use within the med-
Kocis/Vrana 
ically complex patient population (e.g., oncology, AIDS, epilepsy, and geriatric). In addition to the drug-drug interactions involving OTC, herbal, and prescription medications, there can be DIETARY-drug interactions such as when grapefruit INHIBITS the metabolism of another medication by the CYP3A4 enzyme. There is potential HERBAL-drug interaction when St. John's Wort INDUCES the metabolism of another medication by the CYP3A4 enzyme $[38,39]$. Additionally, herbal supplements (e.g., Black Cohosh and Echinacea) are sometimes paired with cannabis. Unfortunately, these added herbal supplements themselves also have known drug-drug interactions [40].

\section{Cannabinoid (as PRECIPITANT) Affecting Metabolism of OTHER Medications}

The online supplementary material provides a list of 139 medications that could have a potential drug-drug interaction with a cannabinoid (prescription, OTC, or illicit) (see www.karger.com/doi/10.1159/000507998 for all online suppl. material). Figure 2 provides a detailed illustration of this online supplementary material. These medications are presented in alphabetical order and primarily identify the cannabinoid as a PRECIPITANT medication that either INHIBITS, INDUCES, or competes as a SUBSTRATE for a specific enzyme/receptor of an OBJECT medication. Colors, directional arrows, and capitalization are all utilized to provide visual cues to identify the type of drug-drug interaction. Additionally, the source and date of this information are provided.

Although two or more medications may compete for the same enzyme, this may not be clinically significant when a medication has a broad therapeutic concentration range and with minor fluctuations having minimal clinical impact. Therefore, in an effort to reduce any potential false alerts, alert fatigue, and to provide a manageable drug-drug interaction list, the medications that only have an NTI are highlighted in this report.

The supplementary material list can be viewed online at the Penn State College of Medicine, Department of Pharmacology website. It is anticipated that as new medications are approved and evidence provided for observed/replicated cannabinoid drug-drug interactions, one of the goals of this project was to create a single list that is periodically updated.

This list is further categorized by the PRECIPITANT medications (dronabinol, nabilone, $\mathrm{CBD}$, and nabiximols), the cannabinoid class (THC/CBD) that it belongs to, as well as illustrating a potential increase $(\uparrow)$ and/or decrease $(\downarrow)$ of the drug effect of the OBJECT medication.

It is interesting to note that, for several OBJECT medications (e.g., acenocoumarol), there is the potential to increase $(\uparrow)$ and/or decrease $(\downarrow)$ drug effects based on a number of different metabolic enzymes and the fact that the PRECIPITANT may INHIBIT but also INDUCE expression of enzyme activity (e.g., CYP1A2, CYP2C9, CYP2C19, and CYP3A4). The check mark " $\sqrt{ }$ " identifies whether the PRECIPITANT is an INHIBITOR or INDUCER of a specific metabolizing enzyme.

The FDA Center for Drug Evaluation and Research (CDER) draft guidance document titled "Clinical Drug Interaction Studies - Study Design, Data Analysis, and Clinical Implications Guidance for Industry" describes a WEAK INHIBITOR " $\sqrt{ }$ (Weak)" as "a drug that increases $(\uparrow)$ the Area Under the Curve (AUC) of a sensitive index SUBSTRATE of a given metabolic pathway by $\geq 1.25$-fold to $<2$-fold." The MODERATE INHIBITOR " $\sqrt{ }$ (Mod)" is defined by the FDA as a "drug that increases $(\uparrow)$ the AUC of a sensitive index SUBSTRATE of a given metabolic pathway by $\geq 2$-fold to $<5$-fold." [41]. Finally, the source of the drug-drug interaction information (e.g., PI, FDA. gov, and DrugBank.ca) and date are provided.

\section{Medical Marijuana, Unregulated CBD Oil, and Recreational Marijuana}

Prior discussions within this article have been predicated on information gathered from regulatory agency approved cannabinoid manufacturer PI, supplemented with the FDA "Drug Development and Drug Interactions: Table of Substrates, Inhibitors and Inducers" online document [22] and the DrugBank database [23]. While these drug-drug interactions are important for the relatively small patient populations for which the drugs are intended, perhaps the broader importance is derived from the recent deregulation of CBD oil (hemp oil) and the steady increase in states and countries legalizing recreational and medical marijuana.

The use of medical marijuana (whether smoked or in extracts), CBD oil, or recreational marijuana can deliver a highly variable cannabinoid concentration. As has been seen in Colorado, there has been a concerted effort to increase the $\Delta^{9}$-THC content of recreational marijuana [42]. While typical Marinol ${ }^{\circledR}\left(\Delta^{9}\right.$-THC) prescriptions are dispensed as $2.5 \mathrm{mg}, 5 \mathrm{mg}$, or $10 \mathrm{mg}$ capsules, recreational marijuana will provide cannabinoids at concentrations 10- to 100-fold higher; therefore, potential drug-drug in- 


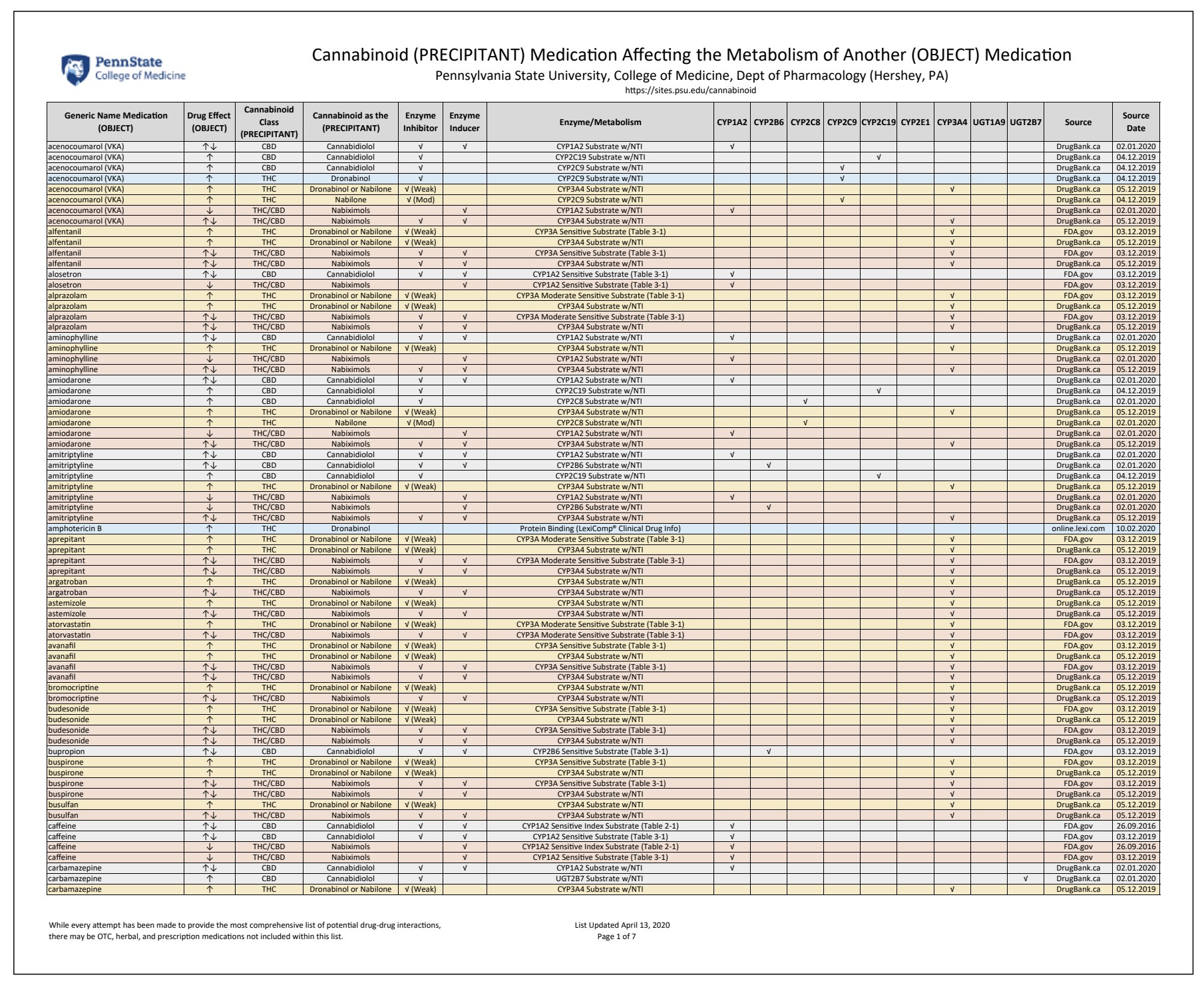

Fig. 2. Cannabinoid (PRECIPITANT) Medication Affecting the Metabolism of Another (OBJECT) Medication (see www.karger.com/doi/10.1159/000507998).

teractions will be exacerbated. Patients may be less likely to accurately report their recreational marijuana frequency and amount of use. Therefore, it is incumbent on the healthcare provider to inquire as to this use. For example, screening for use of cannabinoid-containing products is now advocated for select cardiovascular patient populations [43]. Finally, plant-derived products may contain myriad other compounds (e.g., cannabinoids, flavonoids, and terpenes) that may increase the risk of unintended drug-drug interactions.

\section{Limitations}

While every attempt has been made to provide the most up-to-date and comprehensive list of drug-drug interactions, there may be OTC, herbal, and prescription medications that are not included within this publication or online supplementary material. Except for selected instances, the medications contained in these lists do not describe their active metabolites and associated metabolizing enzymes. The source of data may, at times, be inherently outdated due to the publication date or revision date of the sourced information (e.g., PI). When compiling this list of drugdrug interactions, tables within the FDA "Drug Develop-
Kocis/Vrana 
ment and Drug Interactions: Table of Substrates, Inhibitors and Inducers," online document [22] were last updated on September 26, 2016 and other tables updated on December 3rd, 2019. The DrugBank database [23], which is updated frequently, was last accessed between November 2019 and February 2020. At times, the format of the $\Delta^{9}$-THC and CBD cannabinoid PI varied; therefore, the drug-drug interaction information was at times challenging to compare and contrast. The pharmaceutical cannabinoid manufacturer did not, at times, undertake formal drug-drug interaction studies and report only general and nonspecific case reports (e.g., marijuana smoking).

\section{Discussion}

Although the focus of this article was to identify and describe specific $\Delta^{9}$-THC and CBD cannabinoid drugdrug interactions, there are physiologic effects that can be attributed to cannabinoid use that may impact the cardiovascular, cerebrovascular, respiratory, temperature, and coagulation systems for the hospitalized and surgical patients [44]. The patient's current use of cannabinoids (whether it be prescription, OTC, and/or illicit) should be taken into consideration when medically managing a patient during a hospital stay or when selecting a medication to treat pain, nausea, and/or vomiting in the outpatient setting $[45,46]$. The withdrawal of a cannabinoid (more specific to heavy recreational cannabis use) may precipitate the cannabis withdrawal syndrome [44]. In addition, there have been reports of patients who regularly use recreational cannabis and then require higher doses of propofol for sedation [47].

There have been various published case reports and journal articles listing P-gp [48], oncology [17, 49], psychotropic [16], transplant $[20,50]$, and other miscellaneous lists of cannabinoid drug-drug interactions [21]. Currently, there is not a comprehensive list of medications that is closely aligned with the cannabinoid manufacturer regulatory agency approved PI. Enzyme SUBSTRATES that have an NTI were included in these drug-drug interaction lists to reduce any potential false alerts, alert fatigue, and to provide a manageable list of the more clinically significant drug-drug interactions. DrugBank was used to identify SUBSTRATES with an NTI. These lists of potential drugdrug interactions include medications that are metabolized by the cytochrome P450 enzymes, the UGT enzymes and those that compete as metabolism SUBSTRATES with medications that have an NTI. Additionally, other potential drug-drug interactions are the result of those highly pro-

THC and CBD Drug-Drug Interactions tein-bound medications, those metabolized by the CYP1A2 enzyme SUBSTRATE, and further INDUCED by smoking.

\section{Conclusions}

With a paucity of formal drug-drug interaction studies, especially in medically complex patient populations (e.g., oncology, HIV, epilepsy, and geriatric), these detailed lists of cannabinoid prescription drug-drug interactions are meant to provide a readily accessible resource for evaluating the use of prescription cannabinoids, as well as OTC and/or illicit or unregulated $\Delta^{9}$-THC and CBD cannabinoid products. While the online supplementary material contains a comprehensive and detailed list of drug-drug interactions, Table 2 provides a concise list of 57 medications, with an NTI, that should be considered in patients taking prescription cannabinoids and/or therapeutic/recreational marijuana. While developing these drug-drug interaction data tables, it was evident there can be multiple drug-drug interactions as the result of the many possible combination of medications and their corresponding metabolizing enzymes. Table 2 provides a starting point for consideration.

This comprehensive drug-drug interaction list is intended to provide a reference when reviewing a patient's medication regimen containing OTC, herbal, and prescription medications and, perhaps, also factoring in the illicit or unregulated use of cannabinoid-containing products. These lists of potential drug-drug interactions are NOT intended to be a substitute for medical decision making, since individual patient characteristics (e.g., gender, age, genomic profile, ethnicity, hepatic function, renal function, and disease state) need to be considered. The specific drug-drug interaction information that is provided in this article and supplementary material is also hosted online at the Pennsylvania State University, College of Medicine, Department of Pharmacology Web site via the following URL: https://sites.psu.edu/cannabinoid.

\section{Acknowledgement}

Our sincere appreciation for the feedback received from the Pharmacists of the Medical Marijuana Advisory Workgroup practicing in the Commonwealth of Pennsylvania.

\section{Disclosure Statement}

None by P.T.K. K.E.V. receives a sponsored research agreement from PA Options for Wellness (a medical marijuana company in the Commonwealth of Pennsylvania). 


\section{Funding Sources}

This work was supported, in part, by a sponsored research agreement (to KEV) from PA Options for Wellness (Harrisburg, PA, USA).

\section{Author Contributions}

P.T.K. and K.E.V. both contributed equally to the conception, design, acquisition of data, analysis, and the interpretation of the data. Additionally, P.T.K. and K.E.V. contributed equally to the drafting and revision of the journal article for its intellectual content.

\section{Disclaimer}

While every attempt has been made to provide the most up-todate and comprehensive list of drug-drug interactions, there may be OTC, herbal, illicit, and prescription medications that are not included. This list of potential drug-drug interactions is intended to provide a reference when reviewing a patient's medication regimen containing OTC, herbal, and prescription medications and, perhaps, also factoring in the illicit or unregulated use of cannabinoid-containing products. These potential drug-drug interactions are NOT intended to be a substitute for medical decision-making, since all individual patient characteristics (e.g., gender, age, genomic profile, ethnicity, hepatic function, renal function, and disease state) need to be considered.

\section{References}

1 Fraguas-Sánchez AI, Torres-Suárez AI. Medical use of cannabinoids. Drugs. 2018;78(16): 1665-703.

2 ElSohly M, Gul W. Constituents of Cannabis sativa. Handb Cannabis. 2014;3:1093.

3 Radwan MM, Wanas AS, Chandra S, ElSohly MA. Natural cannabinoids of cannabis and methods of analysis. In: Cannabis sativa $\mathrm{L}$ botany and biotechnology. Springer; 2017. p. $161-82$.

4 Corroon J, Phillips JA. A cross-sectional study of cannabidiol users. Cannabis Cannabinoid Res. 2018;3(1):152-61.

5 Gaoni Y, Mechoulam R. Isolation, structure, and partial synthesis of an active constituent of hashish. J Am Chem Soc. 1964;86(8):1646-7.

6 National Academies of Sciences, Engineering, and Medicine. The health effects of cannabis and cannabinoids: the current state of evidence and recommendations for research. National Academies Press; 2017.

7 Dai H, Richter KP. A national survey of marijuana use among US adults with medical conditions, 2016-2017. JAMA Netw Open. 2019 2(9):e1911936.

8 Hudak J. The Farm Bill, Hemp Legalization and the Status of CBD: An explainer. The Brookings Institution [cited 2018 Dec 14]. Available from: https://www.brookings.edu/ blog/fixgov/2018/12/14/the-farm-bill-hempand-cbd-explainer/.

9 FDA warns 15 companies for illegally selling various products containing cannabidiol as agency details safety concerns. U.S. Food \& Drug Administration (FDA) [cited 2019 Nov 25]. Available from: https://www.fda.gov/newsevents/press-announcements/fda-warns15-companies-illegally-selling-various-products-containing-cannabidiol-agency-details

10 Fasinu PS, Phillips S, ElSohly MA, Walker LA Current status and prospects for cannabidio preparations as new therapeutic agents. Pharmacotherapy. 2016;36(7):781-96.

11 Medical Cannabis: Adverse Effects \& Drug Interactions. Government of The District of Columbia, Department of Health. Available from: https:/doh.dc.gov/sites/default/files/ $\mathrm{dc} /$ sites/doh/publication/attachments/MedicalCannabisAdverseEffectsandDrugInteractions_0.pdf.

12 ElSohly MA, Mehmedic Z, Foster S, Gon C, Chandra S, Church JC. Changes in cannabis potency over the last 2 decades (1995-2014): analysis of current data in the United States. Biol Psychiatry. 2016;79(7):613-9.

13 McPartland JM, Blanchon DJ, Musty RE. Cannabimimetic effects modulated by cholinergic compounds. Addict Biol. 2008;13(34):411-5.

14 Bonn-Miller MO, Loflin MJE, Thomas BF, Marcu JP, Hyke T, Vandrey R. Labeling accuracy of cannabidiol extracts sold online. JAMA. 2017;318(17):1708-9.

15 Keyhani S, Steigerwald S, Ishida J, Vali M, Cerdá M, Hasin D, et al. Risks and benefits of marijuana use: a national survey of U.S. adults. Ann Intern Med. 2018;169(5):282-90.

16 Rong C, Carmona NE, Lee YL, Ragguett RM, Pan Z, Rosenblat JD, et al. Drug-drug interactions as a result of co-administering $\Delta$. Expert Opin Drug Saf. 2018;17(1):51-4.

17 Alsherbiny MA, Li CG. Medicinal cannabispotential drug interactions. Medicines. 2018; 6(1):3.

18 Brown J, Winterstein A. Clinical medicine potential adverse drug events and drug-drug interactions with medical and consumer cannabidiol (CBD) use. J Clin Med. 2019;8:989.

19 Srinivas M, Thirumaleswara G, Pratima S. Cytochrome P450 enzymes, drug transporters and their role in pharmacokinetic drug-drug interactions of xenobiotics: a comprehensive review. Peertechz J Med Chem Res. 2017;3:1-11.

20 Hauser N, Sahai T, Richards R, Roberts T. High on cannabis and calcineurin inhibitors: a word of warning in an era of legalized marijuana. Case Rep Transplant. 2016;2016:1-3.

21 Stout SM, Cimino NM. Exogenous cannabinoids as substrates, inhibitors, and inducers of human drug metabolizing enzymes: a systematic review. Drug Metab Rev. 2014;46(1): 86-95.
22 Drug Development and Drug Interactions: Table of Substrates, Inhibitors and Inducers. U.S. Food \& Drug Administration (FDA) [cited 2017 Nov 14]. Available from: https:// www.fda.gov/drugs/drug-interactions-labeling/drug-development-and-drug-interactions-table-substrates-inhibitors-and-inducers.

23 Wishart DS, Feunang YD, Guo AC, Lo EJ, Marcu A, Grant JR, et al. DrugBank 5.0: a major update to the DrugBank database for 2018 Nucleic Acids Res. 2018;46(D1):D1074-D82.

24 Dronabinol (Marinol $\left.{ }^{\circledR}\right)$. Full Prescribing Information [cited 2017 Aug]. Available from: https://www.rxabbvie.com/pdf/marinol PI.pdf.

25 Dronabinol (Syndros ${ }^{\circledR}$ ). Full Prescribing Information [cited 2018 Sep]. Available from: http://syndros.com/wp-content/uploads/2019/06/SYNDROS-label.pdf.

26 Nabilone (Cesamet ${ }^{\circledR}$ ). Drug Label Information: DailyMed. U.S. National Library of Medicine [cited 2015 May 7]. Available from: https://dailymed.nlm.nih.gov/dailymed/drugInfo.cfm?setid=bb582d64-0f51-11df-8a39$0800200 c 9 a 66$.

27 Letter (Data on File: VV-MED-04647). Carlsbad, CA: Greenwich Biosciences. Cannabidiol (Epidiolex $\left.{ }^{\circledR}\right)$.

28 Cannabidiol Epidiolex $^{\circledR}$ ). Full Prescribing Information [cited $2018 \mathrm{Dec}$ ]. Available from: https://www.epidiolex.com/sites/default/ files/EPIDIOLEX_Full_Prescribing_Information.pdf.

29 Sativex Oromucosal Spray. Summary of Product Characteristics (SmPC). GW Pharma Ltd [cited 2019 Sep 3]. Date of Revision of Text 2019 Apr 27. Available from: https://www. medicines.org.uk/emc/product/602/smpc.

30 Nabiximols - DrugBank. The Canadian Institutes of Health Research, Alberta Innovates-Health Solutions, and The Metabolomics Innovation Centre (TMIC) [updated Version 5.1.4, Released 2019 Feb 7]. Available from: https://www.drugbank.ca/drugs/ DB14011. 
31 Nabiximols ClinicalTrials.gov. U.S. National Library of Medicine. Available from: https:// clinicaltrials.gov/ct $2 /$ results? $\operatorname{cond}=\&$ term $=$ nabiximols $\& \quad$ cntry $=$ US $\& \quad$ state $=\&$ city $=\&$ dist $=$.

32 Rowland A, Miners JO, Mackenzie PI. The UDP-glucuronosyltransferases: their role in drug metabolism and detoxification. Int $\mathrm{J}$ Biochem Cell Biol. 2013;45(6):1121-32.

33 Kiang TK, Ensom MH, Chang TK. UDPglucuronosyltransferases and clinical drugdrug interactions. Pharmacol Therapeut. 2005;106(1):97-132.

34 Scheife RT. Protein binding: what does it mean? DICP. 1989;23(7-8):S27-31.

35 Zevin S, Benowitz NL. Drug interactions with tobacco smoking. An update. Clin Pharmacokinet. 1999;36(6):425-38.

36 Dobrinas M, Cornuz J, Pedrido L, Eap CB. Influence of cytochrome P450 oxidoreductase genetic polymorphisms on CYP1A2 activity and inducibility by smoking. Pharmacogenet Genomics. 2012;22(2):143-51.

37 Zhou S-F, Wang B, Yang L-P, Liu J-P. Structure, function, regulation and polymorphism and the clinical significance of human cytochrome P450 1A2. Drug Metab Rev. 2010; 42(2):268-354.

38 Kiani J, Imam SZ. Medicinal importance of grapefruit juice and its interaction with various drugs. Nutr J. 2007;6:33.
39 Markowitz JS, Donovan JL, DeVane CL, Taylor RM, Ruan Y, Wang J-S, et al. Effect of St John's wort on drug metabolism by induction of cytochrome P450 3A4 enzyme. JAMA. 2003;290(11):1500-4.

407 Medicinal Herbs to Pair With Cannabis: Written by Anna Wilcox (Herb.co) [cited 2019 Aug 19]. Available from: https://herb. co/learn/best-herbs-to-mix-with-weed/.

41 Clinical Drug Interaction Studies: Study Design, Data Analysis, and Clinical Implications. Guidance for Industry (Draft Guidance for Comment Purposes Only). U.S. Food \& Drug Administration (FDA) [cited 2018 Aug 24]. Available from: https://www.fda.gov/regulatory-information/search-fda-guidancedocuments/clinical-drug-interaction-studies-study-design-data-analysis-and-clinicalimplications-guidance.

42 Stuyt E. The problem with the current high potency THC marijuana from the perspective of an addiction psychiatrist. Mo Med. 2018; 115(6):482-6.

43 DeFilippis EM, Bajaj NS, Singh A, Malloy R, Givertz MM, Blankstein R, et al. Marijuana use in patients with cardiovascular disease: JACC review topic of the week. J Am Coll Cardiol. 2020;75(3):320-32.
44 Echeverria-Villalobos $\mathrm{M}$, Todeschini $\mathrm{AB}$, Stoicea N, Fiorda-Diaz J, Weaver T, Bergese SD. Perioperative care of cannabis users: a comprehensive review of pharmacological and anesthetic considerations. J Clin Anesth. 2019;57:41-9.

45 Beaulieu P, Boulanger A, Desroches J, Clark AJ. Medical cannabis: considerations for the anesthesiologist and pain physician. Can J Anaesth. 2016;63(5):608-24.

46 Bakshi C, Barrett AM. Impact of recreational and medicinal marijuana on surgical patients: a review. Am J Surg. 2019;217(4):783-6.

47 Twardowski MA, Link MM, Twardowski NM. Effects of cannabis use on sedation requirements for endoscopic procedures. J Am Osteopath Assoc. 2019;119(5):307-11.

48 Zhu HJ, Wang JS, Markowitz JS, Donovan JL, Gibson BB, Gefroh HA, et al. Characterization of P-glycoprotein inhibition by major cannabinoids from marijuana. J Pharmacol Exp Ther. 2006;317(2):850-7.

49 Bouquié R, Deslandes G, Mazaré $\mathrm{H}$, Cogné $\mathrm{M}$, Mahé J, Grégoire M, et al. Cannabis and anticancer drugs: societal usage and expected pharmacological interactions: a review. Fundam Clin Pharmacol. 2018;32(5):462-84.

50 Motycka C, Egelund EF, Thomas C. The impact of medical marijuana on pharmacy practice. Adv Pharmacol Pharm. 2018;6(1):12-7. 